\title{
Editorial
}

\section{Crossing boundaries: water and the rights paradigm}

There is limited water on Earth. With an exponentially growing global population and ever expanding needs, humanity is blindly and with disquieting determination venturing into unchartered territory. Some refer to this unchartered territory as an 'unsafe operating space' ${ }^{1}$ for humans in the Earth system. There is a realization that we are crossing those planetary boundaries that represent the dynamic biophysical 'space' of the Earth System within which humanity has to date evolved and thrived. ${ }^{2}$ These planetary boundaries 'respect Earth's "rules of the game" or, as it were, define the "planetary playing field" for the human enterprise'. 3

The argument that we are now pressing against planetary boundaries seeks to refocus our attention on the non-negotiable planetary preconditions that humanity needs to respect in order to avoid the risk of calamitous global environmental change. Although 'global freshwater use', as one of nine planetary boundaries, has not yet been crossed, scientists believe that '[w]ater-induced thresholds at the continental or planetary scale may be crossed as a result of aggregate sub-system impacts at local (e.g., river basin) or regional (e.g., monsoon system) scales ... caused both by changes in water resource use and climate change-induced shifts in the hydrological cycle' ${ }^{4}$ However, we do not need to conceptualize the issue in terms of a boundary threshold in order to appreciate the dangers represented by the fact that water, as a critical life-supporting medium, is polluted beyond the limits of its carrying capacity; is consumed in ways that negatively impact the integrity of the ecosystems it maintains; is diminished by climate change impacts; and is unfairly distributed among users (humans inter se and humans vis-àvis voiceless non-human entities) - a reality with dire inter- and intra-generational and ecological justice consequences. Realizing that water is an integral part of the Earth system and that this very system is now increasingly 'operating in a no-analogue state', ${ }^{5}$ means that social-ecological relationships will increasingly be characterized by intense competition between users, with acute conflicts arising over water between humans and between humans and non-human entities.

How should we philosophically and, above all, practically approach the many issues, including the conflicts, which inevitably arise in the complex social-ecological relationships around water? One fairly predictable response is, of course, to situate the water debate within the rights paradigm. To be sure, water's centrality to social-ecological

1. Rockström Johan et al., 'Planetary Boundaries: Exploring the Safe Operating Space for Humanity' (2009) 14(2) Ecology and Society 1-33.

2. Ibid., at 5 .

3. Ibid., at 5 .

4. Ibid., at 16 .

5. International Geosphere-Biosphere Programme, '2001 Amsterdam Declaration on Earth Science' <www.igbp.net/about/history/2001amsterdamdeclarationonearthsystemscience.4. 1b8ae20512db692f2a680001312.html> accessed 8 August 2012. 
systems inevitably inserts it emphatically into the core concerns of the rights domain. Perhaps more than any other environmental medium, water represents a perfect embodiment of - and at the same time - a reason for - and object of - the pervasive tensions, both real and apparent, that pervade the complex, multi-dimensional and multi-layered relationships between (human) rights and the environment.

Focusing on some of the dimensions of these tensions arising in the water context, Lubett and Akhtarkhavari's article in this issue of the Journal of Human Rights and the Environment directs our attention explicitly towards clashing development interests that revolve around water in post-war South Sudan. They argue that the long-term development and prosperity of fragile communities in South Sudan are manifestly intertwined with the way in which access to water is governed and they illustrate the potential of environmental human rights to frame the politics of how water is accessed in the world's youngest nation. More specifically, the authors interrogate the extent to which the human rights paradigm could respond to the many contemporary concerns around the central role of water in social-ecological systems. They argue that the utilization of the language of human rights more generally has both positive and negative consequences, depending on the situation, culture, history and government where it is raised. Water may be universally accepted as a necessity for human survival, but situational demands are highly specific to region, climate and geography - and this will directly influence the utility of resort to a human right to water, as opposed to, for example, a human right to a healthy environment.

The many tensions in the context of water are patently grounded in and arise because of needs that revolve around two distinct, yet very much interdependent, foci: human needs on the one hand, and ecological or ecosystem needs on the other. ${ }^{6}$ Within this context of needs and tensions, water is ultimately proof of the inextricable link between ecosystems and the social systems that use and depend on them. ${ }^{7}$ But water is also a condition for synergy or harmony between social and ecological relations. Where water is absent, any balance in complex social-ecological systems will falter: the boundary will be crossed as it were, and, ultimately, in the worst scenarios, human and non-human life alike will cease to exist. This drives at something more profound: the inescapability of ceaseless flows between bodies bodies of humans, of non-human creatures and of all lively matter, especially - in this instance - water.

While the traditional description of water in the broader context of social-ecological relationships often manifests at a highly abstract level, water is decidedly intimate and fundamental to our profound human continuities with 'the world'. Perhaps because water is so close to us (indeed part of us as Neimanis argues in this issue), we humans should see water not only in terms of its 'removed' functions in maintaining ecosystems, but also approach it from a transformed ontological understanding: we are water, in the same way that a plant or animal is water. Neimanis' article - which suggests a rich, watery ontology - points directly to the prevailing ineffectiveness of protecting and promoting those rights associated with water. She powerfully argues that the problem is not only one of political will or of implementation mechanisms; there may also be an inability in the human rights paradigm to respond robustly to water

6. N LeRoy Poff et al., 'River Flows and Water Wars: Emerging Science for Environmental Decision Making' (August 2003) 1(6) Frontiers in Ecology and the Environment 298-306.

7. C Folke et al., 'Resilience Thinking: Integrating Resilience, Adaptability and Transformability' 2010 15(4) Ecology and Society 1-10. 
as water. Contending that current rights discourse may be fundamentally limited by its intrinsic atomism and anthropocentrism, Neimanis turns to post-humanist feminism for an expanded imaginary of 'what water can be, of what water might need, and of our human responsibilities within a more-than-human aqueous ecology'. In doing so, however, Neimanis does not reject rights discourse and its potential utility. She points to the political traction that social justice discourse (as embedded in human rights) has gained in the water context, and acknowledges that this discourse has 'worlded' new spaces and opportunities for alternative imaginaries. Thus, the human right to water could remain relevant and valuable, especially in so far as it has the potential to 'respond to a particular kind of relation between human bodies and watery nature'.

The atomistic conception of ourselves and our relation to water as a resource, alluded to above, reflects our instinctive tendencies to compete with each other to secure unfettered and, ideally, indefinite access to water, but also suggests our innate and selfish tendency to prioritize immediate human needs at the expense of ecological integrity and ecosystem needs viewed over a longer time frame. We will do whatever it takes to survive. Yet, in this effort for survival, particularly as mediated through capitalist regulatory structures, it is the marginalized and impoverished members of society, including the 'water poor', who usually lose out. As Grear has pointed out in a more general context: '[a]long with the multitudes of defenceless living species adversely affected by the degradation of our shared environment, millions of human beings also suffer the deleterious effects and destructive impacts of human activity, particularly in the context of economic globalization'. ${ }^{8}$

As a result of its commodification, water has steadily become the object of globalized economic processes - producing many vexing questions related to, for example: the role of the state and the private corporation in providing water to people; privatization of water services; and the role of domestic water regimes to provide water in a manner that is fair, equitable, transparent, affordable and sustainable. In their article, Morgan and Seshadri explore the tensions inhabiting the uneasy mix of public responsibilities to provide access to water and private water regimes. The authors highlight the fact that traditionally, collective social and economic entitlements embedded in a social movement for structural change usually either focused on collective responsibility instituted through public authorities, or were tied more closely to private property rights and to private legal entities that compete to provide services in a market setting. Yet, the stark division between these two very different approaches to water provision is becoming increasingly blurred with the rise of hybrid governance structures that have become pervasive in the institutional imagination of those responding to the challenge of access to water. Social enterprises that channel profits to support a social or environmental cause provide an example of hybrid governance institutions with the potential to bridge the divide between a strictly public and a purely private approach to the provision of water. Specifically pointing to the relationship between social enterprise and social activism, the authors interrogate an assumption of uni-dimensional or static relationships between these forms of response, arguing that there are multiple diverse relationships possible between them, including oppositional, evolutionary, complementary and dialectical relations. The hybrid space between activism and enterprise and the shifting dynamics between social activism and enterprise are empirically illustrated with reference to examples from India and Bolivia.

8. A Grear, 'Editorial: Where Discourses Meet' 2010 1(1) Journal of Human Rights and the Environment $1-6$ at 1. 
McIntyre continues the theme of water provision in this special issue with a specific focus on Ireland. His contribution explores current reforms of the Irish water sector, which are occurring as a result of the austerity measures imposed upon Ireland under the terms of the 2009 European Union/International Monetary Fund financial bail-out package. McIntyre interrogates the extent to which the discourse in international law concerning the emerging global human right to water and sanitation might exert any influence on the future legal and institutional arrangements for the Irish water sector. In the absence of any provision of Irish and European Union law that expressly supports the right of access to water or to sanitation, the article turns to an innovative interpretation of certain constitutional and statutory provisions in Ireland and in the European Union that might be interpreted so as to encapsulate and guarantee key elements of the human right to water and sanitation. Finally, McIntyre proposes a range of considerations that countries such as Ireland should consider when transforming water regimes in order to ensure that any such reforms are conducive to the spirit, purport and objectives of universal human rights to water and sanitation that exist at the supra-national level.

All of the contributions to this edition, in their different ways, point to the paradoxical complexities surrounding boundaries - their power as limits, their constructed nature, their contingency, their incompleteness as demarcations of far more elusive dynamics - and the challenges facing law and legal responses in their light. Humans hold a particular position in the biosphere as ecological and as moral agents with the capacity to destroy it. We humans are also in and of the environment and responsible to it. ${ }^{9}$ We carry a tremendous responsibility of care for each other and for non-human life, for while humans are undoubtedly destroyers of ecosystems, we are also in a unique position to respond to and change the lethal behaviours that make us paradoxically so powerful and so vulnerable in relation to the biosphere. Increasingly, we can see that multiple forms of vulnerability are constructed, aggravated and perpetuated by our own activities ${ }^{10}$ - and by the power we exert over the vulnerable biosphere and its many and varied components. As vulnerable, but powerful, entities that live in an increasingly unpredictable geological epoch, we cannot afford to cross the planetary boundaries that are now looming closer than ever before, for these boundaries have the quality of both finitude and finality. The rules of the game have been set for the human enterprise on this planetary playing field. We ignore them at our peril.

Louis J Kotzé ${ }^{11}$ (Assistant editor and special edition editor) Professor of Law, North-West University, South Africa; Vising Professor of Environmental Law, University of Lincoln; Deputy-director Global Network for the Study of Human Rights and the Environment (www.gnhre.org)

9. Evadne Grant, Louis Kotzé and Karen Morrow 'Human Rights and the Environment: In Search of a New Relationship. Synergies and Common Themes', to appear in Oñati SocioLegal Series (2013) - Human Rights and the Environment: In Search of a New Relationship. 10. A Grear, 'The Vulnerable Living Order: Human Rights and the Environment in a Critical and Philosophical Perspective' 2011 2(1) Journal of Human Rights and the Environment 23-44. 11. The guest editor wishes to thank the Academy of Finland for their financial support under the project: 'Legal frameworks to promote water security'. The funding has partly contributed to the editorial process for this special issue. 